\title{
GEOBASEUEFS: NOVA FERRAMENTA DIDÁTICA PARA O ENSINO SUPERIOR NA UEFS
}

\author{
Brenda de Souza Santino'; Joselisa Maria Chaves ${ }^{2}$ \\ 1. Bolsista PIBIC/CNPq, Graduanda em Agronomia , Universidade Estadual de Feira de Santana, e-mail: \\ brendda.28.bs@gmail.com \\ 2. Orientadora, Departamento de Ciências Exatas, Universidade Estadual de Feira de Santana, e-mail: \\ joselisa@uefs.br
}

PALAVRAS-CHAVE: base de dados; ensino-aprendizagem; geotecnologias.

\section{INTRODUÇÃO}

Compreende material didático como todo e qualquer recurso utilizado em um procedimento de ensino, visando à estimulação do aluno e à sua aproximação do conteúdo (Dittrich, 2008). Nesse sentido a criação de meios onde o estudante possa atrelar os conhecimentos adquiridos das disciplinas ao seu cotidiano, facilitam o processo de aprendizagem e fixação dos conteúdos.

Com a chegada da educação mediada por computadores, o uso de recursos educacionais digitais para aquisição e transmissão de conhecimentos gera um ambiente atrativo para o desenvolvimento de sistemas, que possam facilitar o funcionamento qualitativo dos ambientes de ensino-aprendizagem (Afonso et al. 2011). Nesse intuito foi criada a base de dados GEOBASEUEFS, que busca agrupar os diversos conhecimentos existentes relacionados à cidade de Feira de Santana, em uma única plataforma online e digital servindo como fonte para consulta em pesquisas realizadas pela comunidade acadêmica.

Valente (1993) destaca a relevância da utilização de recursos computacionais como um meio didático multidisciplinar, sendo a GEOBASEUEFS, uma ferramenta que pode apresentar um grande potencial ao ser aplicada no ambiente universitário, uma vez que a variedade de conteúdo presente em seu banco pode gerar inúmeras possibilidades e formas de uso da mesma, como criação de mapas, apostilas, aulas e oficinas. Dessa forma a tecnologia serve para enriquecer o ambiente educacional, propiciando a construção de conhecimentos por meio da atuação ativa, crítica e criativa por parte de alunos e professores (Moran, 1995; Venturi, 2012 e Chuerubim et al, 2014).

O objetivo desse trabalho é pesquisar como transformar a GEOBASE UEFS em material didático para as disciplinas Pedologia, Geociências II e Sensoriamento Remoto que estão presentes na matriz curricular do curso de Agronomia.

\section{MATERIAL E MÉTODOS}

O trabalho foi desenvolvido em cinco etapas. Para a criação do material didático a princípio foi realizada uma revisão bibliográfica onde foi estudado de que forma a GEOBASEUEFS poderia ajudar no processo de aprendizagem dos conteúdos de Geociências II, Pedologia e Sensoriamento Remoto.

Em seguida foi feita a elaboração de um minicurso baseado nos conceitos de Sensoriamento Remoto, de forma que pudesse ser mostrada a aplicação das Geotecnologias no cotidiano dos discentes, nas disciplinas do curso de Agronomia e também na sua formação profissional.

Depois foi realizada a seleção dos dados contidos na base de dados que viriam ser utilizados para a construção do material didático, referentes parte prática do minicurso. Foi escolhida uma imagem satélite Landsat- 8 datada do dia 30 de janeiro de 2016, de composição colorida, com bandas multiespectrais, e resolução espacial 30 metros, com cena referente a cidade de Feira de Santana. Também foram selecionados 
dois arquivos vetoriais, shapes, correspondentes aos limites de Feira de Santana e as principais rodovias da cidade.

$\mathrm{Na}$ quarta etapa houve a aplicação do minicurso, que foi realizado com discentes do curso de Agronomia, no LAPIG (Laboratório de Processamento de Imagens Georreferenciadas), a fim de que os alunos tivesse acesso a recursos computacionais como os programas Envi e QuantumGIS, necessários para a realização dos exercícios práticos oferecidos pelo minicurso.

Por último foi feita a avaliação do material construído. Nessa etapa foi aplicado um questionário de avaliação aos discentes que participaram do curso para opinarem e dar novas sugestões em relação também a GEOBASEUEFS.

\section{RESULTADOS E DISCUSSÃO}

Para a criação do material didático, foi pensado uma forma de atrelar os conteúdos abordados nas disciplinas Geociências II, Pedologia e Sensoriamento Remoto, presentes na matriz curricular do curso de Agronomia da Universidade Estadual de Feira de Santana. Assim, foi elaborado um minicurso que teve a duração de três horas, intitulado "Aplicações do Sensoriamento Remoto a partir da ferramenta GEOBASEUEFS", que teve como objetivo principal introduzir conceitos de Sensoriamento Remoto, mostrando sua aplicação para as Ciências Agrárias, assim como, incentivar os discentes a cursar essa disciplina, que é optativa para o curso de Agronomia, relacionando também com Geociências e Pedologia, na finalidade de aproximá-los também de suas realidades, usando como área de estudo a cidade de Feira de Santana.

Antes de iniciar a aplicação do conteúdo, foi distribuído aos discentes um questionário de Sondagem, que foi aplicado na turma duas vezes, a primeira antes de se iniciar o curso, objetivando levantar os conhecimentos prévios dos discentes sobre o assunto e se ter uma ideia do que eles pretendiam aprender na aula, e a segunda vez no final do minicurso, para então verificar se houve ou não alteração nos conhecimentos prévios, além da possibilidade da GEOBASEUEFS poder ser avaliada pelos próprios usuários (Prigol et al, 2008).

$\mathrm{Na}$ primeira parte do minicurso, foi aplicada a teoria, dando uma introdução a conceitos importantes do Sensoriamento Remoto através de aula expositiva auxiliada por slides (figura1). Depois foram mostradas as diversas áreas das ciências agrárias que podem utilizar esses conhecimentos, como na agricultura de precisão, para 0 monitoramento e lavouras, delimitações territoriais, estudos de áreas, entre outras. E por fim, foi apresentada aos discentes a base de dados GEOBASEUEFS.

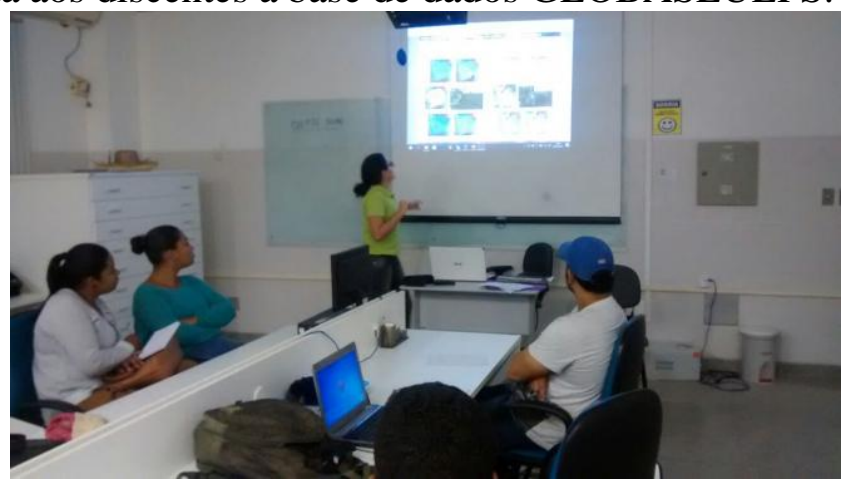

Figura 1. Aula teórica expositiva

Depois foi realizada a parte prática do minicurso (figura 2), que segundo Lunetta (1991) e Prigol et al, (2008), ajudará o discente no processo de interação e no desenvolvimento de conceitos científicos. Iniciou-se com a oportunidade dos alunos de abrirem a base de dados pela internet, a partir de um tutorial que receberam, que auxiliou no processo de pesquisar informações e baixar os arquivos. Após esse primeiro 
contato, foram propostos dois exercícios, o primeiro para utilizar o aplicativo ENVI, para fazer diferentes combinações de bandas espectrais buscando determinar a natureza dos alvos pelas técnicas de sensoriamento remoto, baseando-se no fato de que diferentes materiais são caracterizados por reflectâncias próprias em cada banda do espectro eletromagnético (Wagner, 2004). Nesse sentido os discentes buscaram identificar de forma qualitativa os diferentes componentes da paisagem, como área urbana, rios, lagos, áreas agrícolas, estádios fenológicos de culturas e vegetação nativa, percebendo quais composições são mais adequadas para estudar cada objeto.

Ainda nesse mesmo aplicativo, os discentes puderam fazer também a classificação não supervisionada da imagem através dos algoritmos disponíveis como extensões do programa, o K-MENS que classifica com a distribuição das médias, e o ISODATA que trabalha com distribuição dos pixels. Dessa forma, puderam observar e distinguir os dois métodos percebendo que o K-MENS apresenta maior confusão entre as classes, enquanto o ISODATA discrimina melhor cada alvo separando em uma classe distinta (Ohata e Quintanilha, 2005).

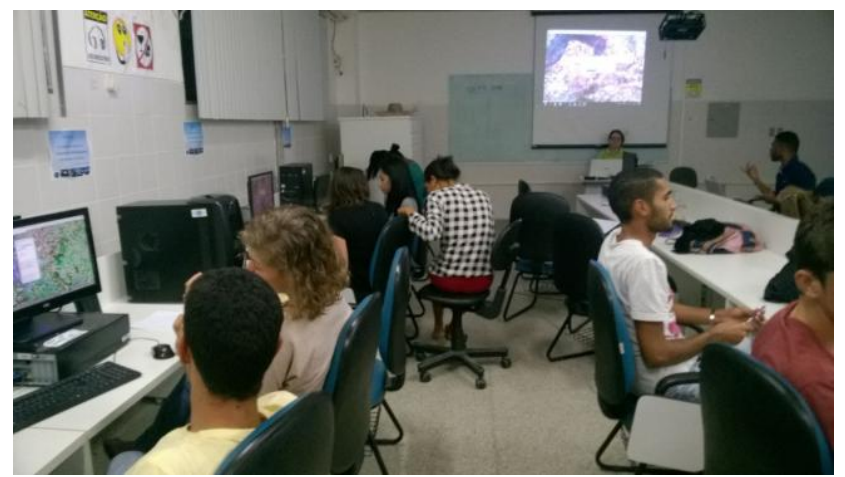

Figura 2. Aula prática realizada: Alunos utilizando o programa ENVI

O segundo exercício foi realizado no Quantum GIS, um software gratuito, licenciado pela GNU (General Public License), baseado em um Sistema de Informação Geográfica (SIG). Sua interface é simples e fácil de ser manuseada, além disso, o programa oferta várias ferramentas que possibilitam visualizar, gerenciar, editar, analisar os dados e compor mapas impressos podendo obter a impressão dos mesmos, entre outros recursos (Torchetto et al, 2014). Nesse programa foi proposta uma atividade de construção de um mapa com os limites territoriais de Feira de Santana. Primeiro foram feitos os downloads no site da GEOBASEUEFS dos arquivos vetoriais a serem usados nessa prática, correspondentes a um shape de limites territoriais e outro contendo as principais rodovias de Feira de Santana. Depois os discentes juntamente com o ministrante do minicurso construíram juntos o mapa, sendo orientados passo a passo, a fim de que eles realizassem o exercício de forma mais rápida absorvendo os conteúdos conjuntamente.

Após o término do curso foi realizado outro questionário de sondagem onde puderam avaliar o minicurso e também a base de dados, nas duas situações ambos tiveram boas avaliações, tanto na abordagem e exposição do conteúdo, material utilizado e didática do minicurso, quanto na utilidade e facilidade de acesso da base de dados. Porém dos onze participantes, sete deram como sugestão que o curso tivesse uma duração maior. Foi perguntado também em quais disciplinas do curso de Agronomia a GEOBASEUEFS poderia ser usada como ferramenta de aprendizado, e além das disciplinas propostas nesse plano (Geociências II, Pedologia e Sensoriamento Remoto), os discentes propuseram também Climatologia, Manejo de Água e Solo, Topografia, Mecanização e Desenho, o que demonstrou que o alcance do conteúdo atual da Base de Dados vai além dos objetivos propostos inicialmente. Como sugestões para melhoria da GEOBASEUEFS, quatro pessoas solicitaram inserir no site mapas de Solos, duas 
pediram para que a base de dados se ampliasse a outros tipos de arquivos, e uma pessoa sugeriu que a quantidade de artigos científicos seja aumentada.

\section{CONSIDERAÇÕES FINAIS}

A partir do minicurso realizado, foi possível perceber a importância da GEOBASE UEFS como ferramenta auxiliadora no processo de Ensino e Aprendizagem dos alunos de graduação do Curso de Agronomia da UEFS, se mostrando como um recurso que poderá ser utilizado nas disciplinas Geociências II, Pedologia e Sensoriamento Remoto, como foram sugeridos pelos próprios discentes. Além disso, o aplicativo se mostrou potencialmente útil para ser usado em outras disciplinas, assim como auxiliador no processo de formação profissional, e execução de outras atividades a serem realizados por profissionais das Ciências Agrárias.

\section{REFERÊNCIAS}

CHUERUBIM, M.L.; PINTO, E.B.; SILVA, G.M.; REBELO, K.M.W. 2014. O uso de geotecnologias no processamento, ajustamento e representação de dados espaciais no processo de ensino e aprendizagem na disciplina de Geomática. Revista Ensino de Ciências, Volume 5- N o 1- Janeiro/Junho.

LUNETTA, V. N. 1991. Actividades práticas no ensino da Ciência. Revista Portuguesa de Educação, v.2, p. 81-90.

MORAN, J. M. Novas tecnologias e o reencantamento do mundo. 1995. Tecnologia Educacional. Rio de Janeiro, vol. 23, n.126, setembro-outubro, p. 24-26.

PRIGOL, S.; GIANNOTTI, S. M. 2007. A importância da utilização de prática no processo de ensino-aprendizagem de Ciências Naturais enfocando a mrofologia da flor. Trabalho de Conclusão de Curso (Graduação em Ciências Biológicas) - Faculdade Assis Gurgacz.

QUINTANILHA, J. A. ; OHATA, A. T. 2005. O uso de algoritmos de clustering na mensuração da expansão urbana e detecção de alterações na Região Metropolitana de São Paulo. In: XII Simpósio Brasileiro de Sensoriamento Remoto, 2005, Goiânia - GO. Anais do XII Simpósio Brasileiro de Sensoriamento Remoto.

TORCHETTO, N. L. ; QUEIROZ, R. ; PEYROT, C. ; PATATT, E. R. ; LANGNER, C. H. ; KOPPE, E. 2014. O uso do Quantum GIS (QGIS) para caracterização e delimitação de área degrada por atividade de mineração de basalto no município de Tentente Portela (RS). Revista Eletrônica em Gestão, Educação e Tecnologia Ambiental , v. 18, p. 719726.

VALENTE, J. A. 1993. Por quê o Computador na Educação? Campinas, SP: Gráfica Central da UNICAMP.

VENTURI, L. A. B. 2012. O uso de técnicas e práticas no ensino aprendizagem e suas contribuições no processo de formação. Revista Entre - Lugar, Dourados, MS, ano 3, n. $6,141-152$ p., $2^{\circ}$ semestre.

WAGNER, A.P.L. 2004. Aplicação de imagens Aster para estudos territoriais no nordeste do estado do Rio Grande do Sul. Porto Alegre: UFRGS, (Dissertação de Mestrado). 